\title{
Module-based subnetwork alignments reveal novel transcriptional regulators in malaria parasite Plasmodium falciparum
}

Hong $\mathrm{Cai}^{1 \dagger}$, Changjin Hong ${ }^{2 \dagger}$, Jianying Gu ${ }^{3+}$, Timothy G Lilburn ${ }^{4 \dagger}$, Rui Kuang ${ }^{2 *}$, Yufeng Wang ${ }^{1,5^{*}}$

From The International Conference on Intelligent Biology and Medicine (ICIBM)

Nashville, TN, USA. 22-24 April 2012

\begin{abstract}
Background: Malaria causes over one million deaths annually, posing an enormous health and economic burden in endemic regions. The completion of genome sequencing of the causative agents, a group of parasites in the genus Plasmodium, revealed potential drug and vaccine candidates. However, genomics-driven target discovery has been significantly hampered by our limited knowledge of the cellular networks associated with parasite development and pathogenesis. In this paper, we propose an approach based on aligning neighborhood PPI subnetworks across species to identify network components in the malaria parasite P. falciparum.

Results: Instead of only relying on sequence similarities to detect functional orthologs, our approach measures the conservation between the neighborhood subnetworks in protein-protein interaction (PPI) networks in two species,

P. falciparum and E. coli. 1,082 P. falciparum proteins were predicted as functional orthologs of known transcriptional regulators in the $E$. coli network, including general transcriptional regulators, parasite-specific transcriptional regulators in the ApiAP2 protein family, and other potential regulatory proteins. They are implicated in a variety of cellular processes involving chromatin remodeling, genome integrity, secretion, invasion, protein processing, and metabolism.

Conclusions: In this proof-of-concept study, we demonstrate that a subnetwork alignment approach can reveal previously uncharacterized members of the subnetworks, which opens new opportunities to identify potential therapeutic targets and provide new insights into parasite biology, pathogenesis and virulence. This approach can be extended to other systems, especially those with poor genome annotation and a paucity of knowledge about cellular networks.
\end{abstract}

\section{Background}

Malaria is a major threat to public health and economic development in endemic regions. About 300-500 million cases are reported, and 1-2 million people die from malaria every year. Children and pregnant women are among the hardest hit of malaria victims. Five parasite species, $P$. falciparum, $P$. vivax, $P$. malariae, $P$. ovale, and

\footnotetext{
* Correspondence: kuang@cs.umn.edu; yufeng.wang@utsa.edu

+ Contributed equally

'Department of Biology, University of Texas at San Antonio, San Antonio,

TX 78249, USA

${ }^{2}$ Department of Computer Science and Engineering, University of Minnesota

Twin Cities, Minneapolis, MN 55455, USA

Full list of author information is available at the end of the article
}

P. knowlesi, cause human malaria. P. falciparum is the most virulent and widespread one.

The continuous morbidity or mortality of malaria is largely due to the rapid development of parasite resistance to currently available drugs and the increasing insecticide resistance of mosquito vectors. It is imperative to search for new lines of antimalarial drug and vaccine targets. The complete genome sequencing of $P$. falciparum and its sibling species and strains [1-6], the subsequent transcriptomic [7-30], proteomic [31-46], metabolic [47-54], interactomic analyses [55-60] and, most recently, next-generation sequencing [61-63] efforts have set the stage for a quantum leap in our understanding of the fundamental processes of 
the parasite life cycle and mechanisms of drug resistance, immune evasion, and pathogenesis. However, the paradigm of -omics driven target discovery has been significantly hampered by our limited knowledge of the cellular networks associated with parasite survival, development, transmission, invasion, and pathogenesis.

We propose to circumvent this limitation using a subnetwork alignment approach. It has been shown that network alignment offers an effective means to elucidate network structure and predict protein orthologs [64-69]. Our approach extends the concept of network alignment to align subnetworks of proteins for measuring their functional relations in a network context. It is particularly useful when the genome of interest suffers from poor annotation due to low or no sequence similarity to known proteins, a significant problem for $P$. falciparum, as over $60 \%$ of the predicted open reading frames (ORFs) were annotated as "hypothetical" without functional assignment [5]. Previously, we developed a supervised learning algorithm for remote homology detection based on support vector machines (SVMs) and profile kernels [70], and predicted a group of novel proteases [71], which were implicated in networks associated with signaling, stress response, cell cycle progression, metabolism, and invasion [72]. In this study, we attempt to identify network components beyond sequence-similarity searches.

PPI network alignment algorithms are designed to match nodes in two PPI networks such that the conserved interactions between the orthologs in the networks are captured or maximized in counts. The current network alignment algorithms are either local or global approaches. Local network alignment [64-69] aims at detecting pairs of subnetwork modules with many functional orthologs. Typically, these algorithms start from conserved regions and expand the regions greedily in the two PPI networks. Global network alignment attempts to find the best consistent mapping of the proteins in the two PPI networks for maximizing the number of conserved interactions. Previous studies tackled the global network problem with Markov Random Field (MRF) [73], combinatorial graph matching by optimization [74-76], and random walk on a Kronecker product graph of two PPI networks [77].

Since $P$. falciparum shares very few orthologous proteins with other species, the conserved interactions between P. falciparum PPI network and the PPI network of model organisms are too few to reveal meaningful alignments. Thus, network alignment is not directly applicable to the study of $P$. falciparum PPI network. Instead of focusing on detecting alignment, we propose to measure the functional relation between $P$. falciparum proteins and the annotated proteins in another species by aligning the neighborhood subnetworks of the two proteins. The neighborhood subnetwork of a protein (called the central protein) contains the nearby neighbors reachable by the protein through a small number of hops in the PPI network. Our assumption is that the neighborhood subnetwork captures information on the functional role of the central protein. Based on this assumption, if two proteins are functional orthologs, their neighborhood subnetworks will share similar paths or other structural patterns. Our subgraph alignment approach is designed to summarize the structural similarity between neighborhood subnetworks for ortholog prediction.

As a proof-of-concept, we chose to predict the components in the transcriptional regulation network in $P$. falciparum. It was chosen because: (1) parasite employs exquisite regulatory machinery on gene expression to assure timely and accurate coordination on parasite growth, development, infection, and virulence. (2) Very little is known about the components, dynamics, and design principles of this network. New discoveries of network components could significantly fill our knowledge gaps and possibly lead to new short lists of proteins that are poorly understood and poorly annotated for functional characterization. The correspondent network used was from Escherichia coli. Detection of network similarities among Eukaryotes and among Prokaryotes have been demonstrated [73,78], but detection of similarities between these two groups is a more challenging problem. The ability to make comparisons across such a wide phylogenetic gap means, firstly, that evolutionarily conserved (and therefore significant) subnetworks can be detected and, secondly, that it is possible to search beyond more closely related strains. This is especially significant in cases like $P$. falciparum, where the immediate relatives reveal comparatively little about its functional subsystems.

\section{Results and discussion}

Module-based subnetwork alignments predicted 1,082 components in transcriptional regulation network in

\section{$P$. falciparum}

It is a common belief that the malaria parasite possesses a complex and orchestrated transcriptional regulatory system $[79,80]$. However, only a small number of transcriptional regulators have been identified, including a conserved set of basic transcription factors [81] and those predicted based on parasite developmental microarray expression profiles and motif analysis [82-84]. A recent study by Bischoff and Vaquero [85] combining literature searches, motif finding, and transcriptomic, proteomic, and interactomic analyses expanded this list to include proteins related to chromatin functions and remodeling.

Our functional module-based subnetwork alignments predicted that 1,082 P. falciparum proteins were functional orthologs of known transcriptional regulators in the E. coli network (Additional file 1). 37\% of these predicted functional orthologs appeared to be "putative 
uncharacterized proteins" or "conserved Plasmodium proteins" of unknown function. This is in agreement with the fact that 10 years after the completion of genome sequencing, the proportion of ORFs with no functional assignment has only been reduced to $45 \%$ [86]. Functional enrichment analysis [87] revealed that 31 Gene Ontology (GO) terms were over-represented $(\mathrm{p}<0.05)$, including those processes that are well known to be associated with transcriptional regulation such as proteolysis [72], response to stimulus, and proteasome activity (Figure 1).

\section{General transcriptional regulators}

The predicted functional orthologs include several general transcriptional regulators (Table 1) that are commonly present in a wide variety of species. The first is basic transcription factor 3b (Accession number PF14_0241). It was found via yeast 2-hybrid (Y2H) analysis [57] to have a direct PPI with a nascent polypeptide associated complex $\alpha$ chain protein (PFF1050w), the erythrocyte binding antigen-181(EBA-181, PFA0125c), and a putative coronin binding protein (PFF1110c), suggesting that it may be involved in protein folding, immune evasion, and cellular actin dynamics (Figure 2). The second is a putative CCAAT-binding transcription factor (PF14_0374). A Y2H assay [57] showed that it had PPIs with six proteins. Two of these proteins are likely involved in global transcription, including (a) a putative NOT1 protein (PF11_0049). Proteins in the NOT1 family were shown to regulate the activity of general transcription factor TFIID [88]; and (b) a conserved Plasmodium protein (PF14_0603) that has a functional domain RPC4 which comprises a subunit of the tRNA specific polymerase RNA Pol III. The third interacting protein is a merozoite surface protein 7 (MSP7) precursor (PF13_0197), which is a regulator of parasite growth and a surface antigen regarded as a potential vaccine target [89]. The fourth protein associated with PF14_0374 is a conserved Plasmodium membrane protein (PF14_0315) that contains two FYVE/PHD zinc fingers for binding to potential target molecules. The remaining two proteins associated with PF14_0374 are 40S ribosomal proteins S10 (PF07_0080) and S20e (PF10_0038), indicating

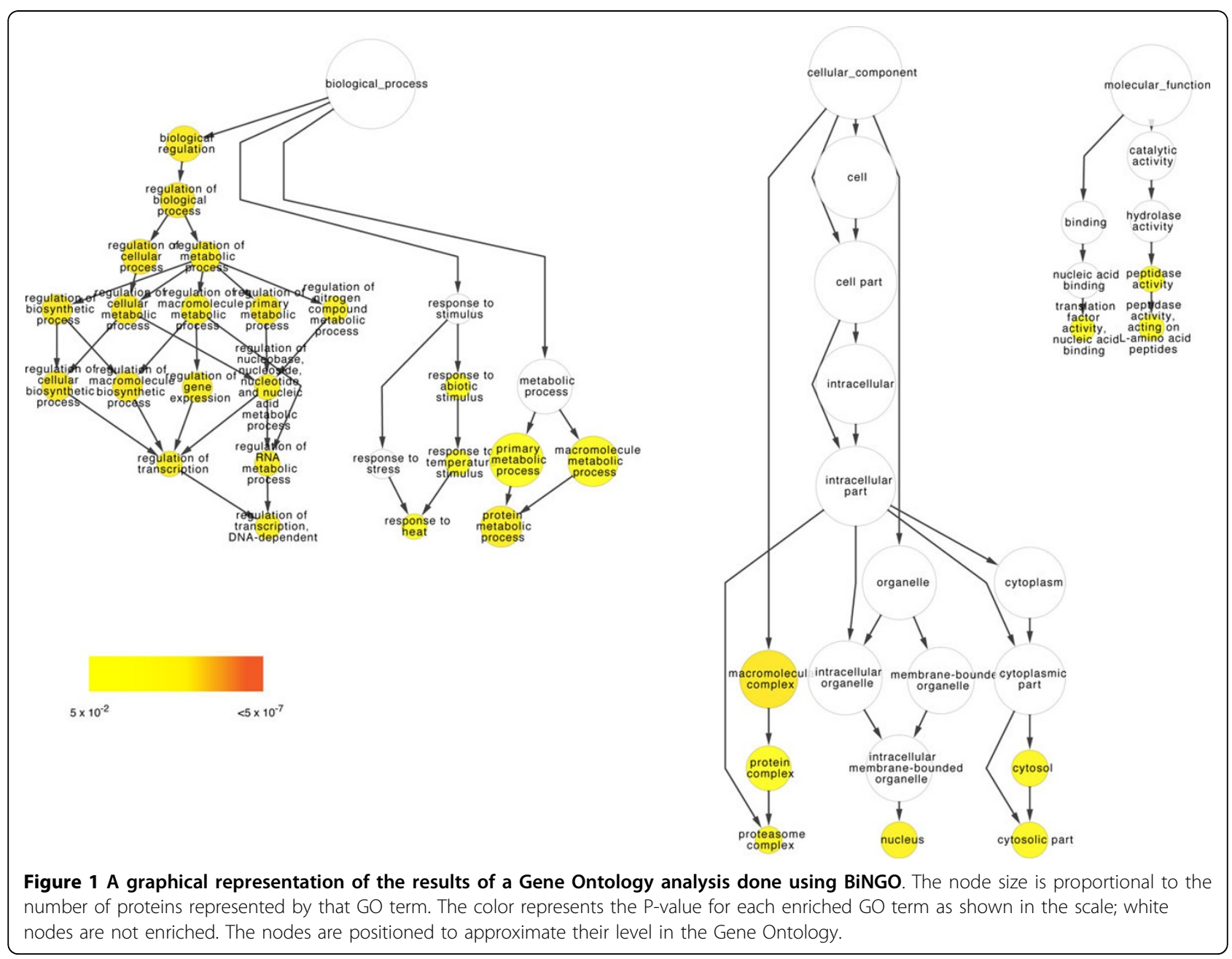


Table 1 Representative $P$. falciparum proteins that were predicted to be involved in transcriptional regulation

\begin{tabular}{|c|c|c|}
\hline Functional category & PlasmoDB Accession Number & Annotation \\
\hline \multirow[t]{3}{*}{ General transcription regulators } & PF14_0241 & putative basic transcription factor $3 \mathrm{~b}$ \\
\hline & PF14_0374 & putative CCAAT-binding transcription factor \\
\hline & PF14_0608 & putative YL1 nuclear protein \\
\hline \multirow[t]{11}{*}{ ApiAP2 } & PFL1085w & putative transcription factor with 1 AP2 domain \\
\hline & PF11_0442 & putative transcription factor with 1 AP2 domain \\
\hline & PF14_0079 & putative transcription factor with 1 AP2 domain \\
\hline & PF11_0091 & putative transcription factor with 1 AP2 domain \\
\hline & PF14_0633 & putative transcription factor with 1 AP2 domain \\
\hline & PFD0985w & putative transcription factor with 2 AP2 domains \\
\hline & PFL1900w & putative transcription factor with 2 AP2 domains \\
\hline & PF07_0126 & putative transcription factor with 2 AP2 domains \\
\hline & PFE0840c & putative transcription factor with 2 AP2 domains \\
\hline & PF11_0404 & putative transcription factor with 3 AP2 domains \\
\hline & PF10_0075 & putative transcription factor with 3 AP2 domains \\
\hline \multirow[t]{2}{*}{ chromosome organization } & PFD0685C & structural maintenance of chromosomes protein 3 homolog \\
\hline & MAL13P1.96 & structural maintenance of chromosomes protein 2 \\
\hline \multirow[t]{9}{*}{ zinc finger proteins } & PF10_0091 & putative zinc finger protein, $\mathrm{C} 2 \mathrm{H} 2$ type \\
\hline & PFL0465c & zinc finger transcription factor (Krox 1$), \mathrm{C} 2 \mathrm{H} 2$ type \\
\hline & MAL7P1.155 & putative zinc finger, $\mathrm{C} 3 \mathrm{HC} 4$ type \\
\hline & PF10_0046 & putative zinc finger, $\mathrm{C} 3 \mathrm{HC} 4$ type \\
\hline & PF10_0186 & putative zinc finger $\mathrm{C}-\mathrm{x} 8-\mathrm{C}-\mathrm{x} 5-\mathrm{C}-\mathrm{x} 3-\mathrm{H}$ type \\
\hline & MAL7P1.68 & putative zinc finger protein, $\mathrm{DHHC}$ type \\
\hline & PF14_0197 & putative zinc finger protein, DNL type \\
\hline & PFD0970c & putative zinc finger protein, CW type \\
\hline & PF10_0143 & putative transcriptional activator ADA2 \\
\hline \multirow[t]{2}{*}{ Others } & PFE0870w & putative transcriptional regulator \\
\hline & PF14_0170 & putative NOT family protein \\
\hline
\end{tabular}

the interactions between transcription and translation (Figure 2).

A putative YL1 nuclear protein (PF14_0608) was predicted to be a transcriptional regulator. It has two functional domains YL1 (Pfam accession PF05764) and YL1 C-terminal domain (PF08265), both of which are typical DNA binding domains. This protein may be related to chromatin remodeling. In addition, a $\mathrm{Y} 2 \mathrm{H}$ assay using this protein as a bait pulled out a chloroquine resistance marker protein (PF14_0463) (Figure 2).

\section{Apicomplexan-specific ApiAP2 transcriptional regulators}

Most interestingly, our subnetwork alignments also predicted 11 putative transcriptional regulators belonging to the Apicomplexan-specific ApiAP2 family. A characteristic feature of this family is the presence of the Apetala2 (AP2) domain. AP2 transcription factors play a pivotal role in floral development in plants [90]. The recent discovery of AP2 in the Apicomplexa, the phylum to which malaria parasites belong, suggested that the ApiAP2 proteins were derived from bacteria or the apicoplast progenitor via transponsons, followed by lineage-specific radiation [91]. These ApiAP2 proteins, in addition to regulating heterochromatin formation and genome integrity, may develop novel parasitespecific functions such as antigenic variation, invasion, and sporozoite development [92-95]. P. falciparum possesses 27 ApiAP2 members. Among the 11 ApiAP2 proteins predicted by our network alignments, five contain a single AP2 domain, four contain two AP2 domains, and two contain three AP2 domains (Figure 3). Analyzing the protein-protein association data from the STRING database [4], in conjunction with the data from the $\mathrm{Y} 2 \mathrm{H}$ assays, temporal microarray experiments, proteomics, and literature, revealed that these 11 ApiAP2 proteins are associated with 1-17 proteins in the cellular networks (Figure 4 and Additional File 2). At least four ApiAP2 proteins (PF07_0126, PFD0985w, PF11_0404 and PF10_0075) have PPIs, suggesting that they play central role in transcriptional regulation. 


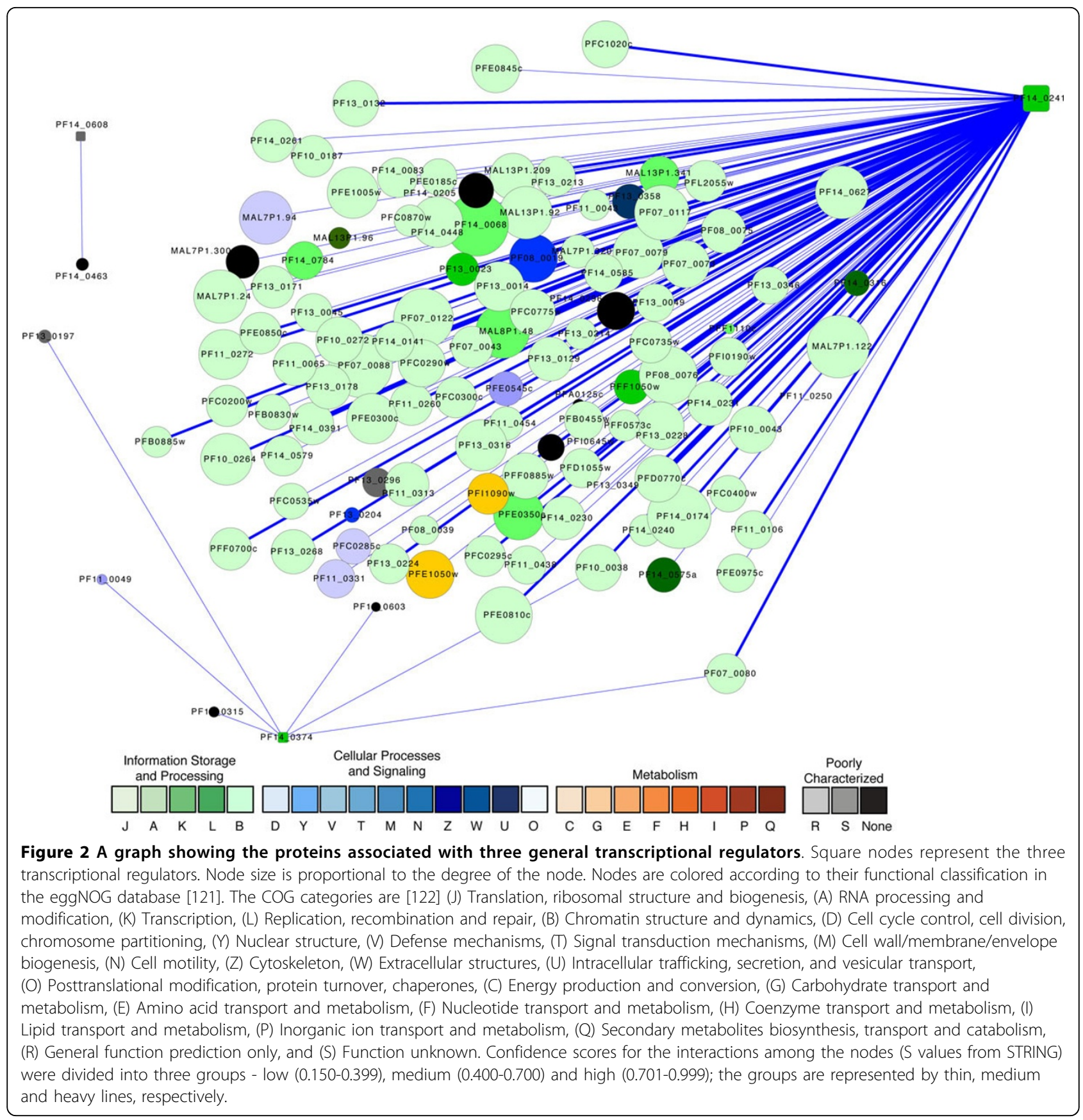

The ApiAP2 protein with highest connectivity is PFD0985w, which has 17 interaction partners (Figure 4). It has direct physical interactions with two other ApiAP2 proteins (PF07_0126 and MAL8P1.153). It is associated with a nucleosome assembly protein (PFI0930c) that is implicated in chromatin remodeling, and a putative $\mathrm{Ndc} 80$ homolog (PFF0785w) that may be a component of the mitotic spindle related to chromosome segregation. It is also associated with three surface antigens including a reticulocyte binding protein 2 homologue a (PF13_0198) which may play a role in determining host-cell invasion specificity [96], an antigen 332 (PF11_0506) in the Duffy binding-like (DBL) protein family which may be related to parasite entry to the host, and an asparagine-rich antigen (PF08_0060). This ApiAP2 protein PFD0985w also appeared to be related to a number of secreted proteins including a putative secreted ookinete protein (PFA0430c), and two proteins that are associated with Maurer's clefts [97], parasite-derived membranous structures within the host cell cytoplasm [PfSec31(PFB0640c), which is a COPII- 


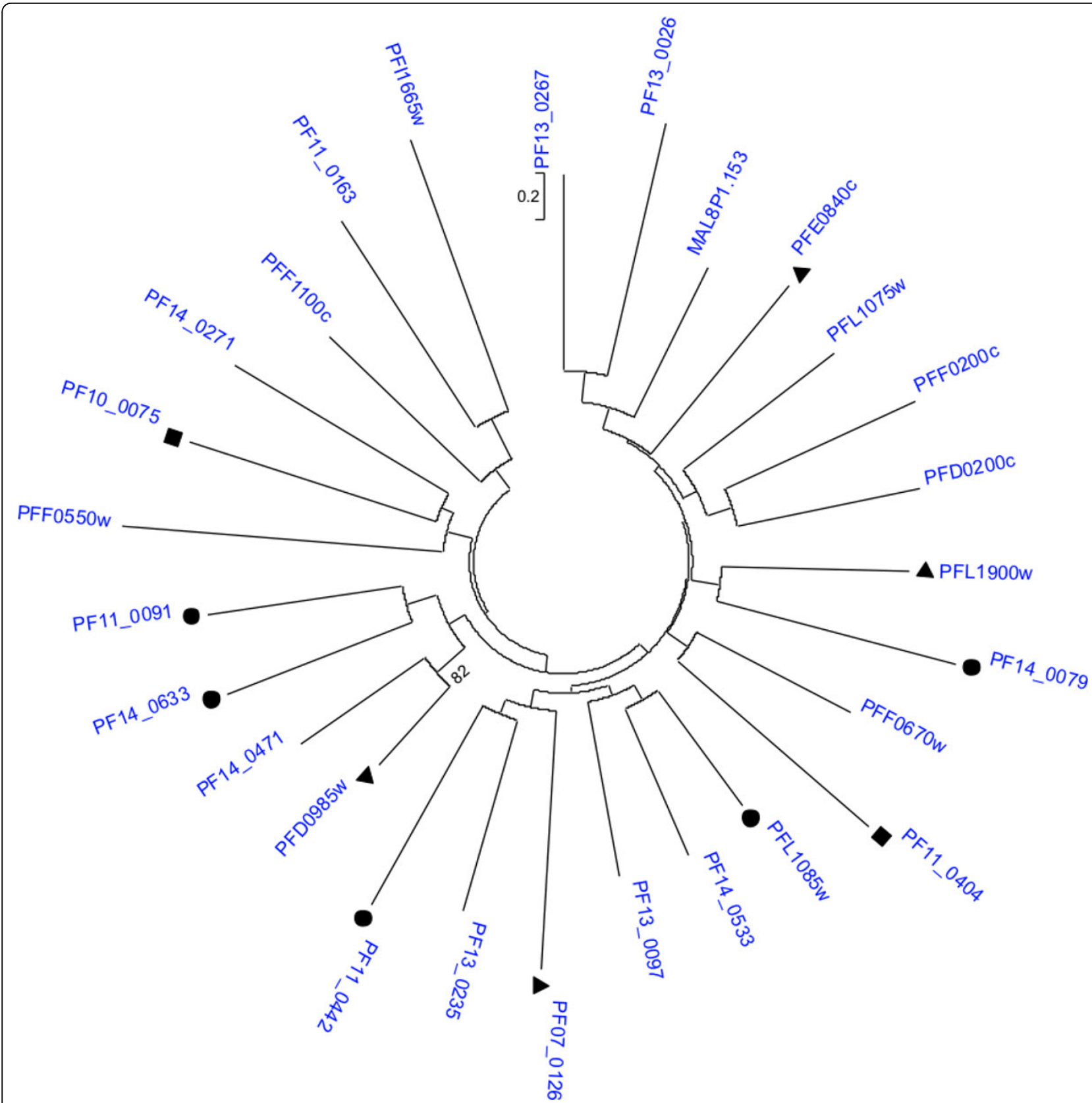

Figure 3 Phylogenetic tree of the ApiAP2 transcriptional regulator family in P. falciparum. The tree was constructed using the neighborjoining method [120]. 11 out of the 27 members were predicted by the subnetwork alignment algorithm. $\bullet$ : ApiAP2 protein with 1 AP2 domain 4: ApiAP2 protein with 2 AP2 domains; : ApiAP2 protein with 3 AP2 domains.

coated vesicle component and PHISTb (PFD0080c)]. In addition, PFD0985w has direct PPIs with the $26 \mathrm{~S}$ proteasome AAA-ATPase subunit RPT3 (PFD0665c), which is a component in ubiquitin-proteasome system for protein degradation, and pyruvate kinase (PFF1300w), an essential enzyme for glycolysis.

The ApiAP2 protein with second largest connectivity is PF07_0126. It has 15 PPI partners (Figure 4) that can be divided into five categories: (1) transcriptional regulation. It is associated with two otherApiAP2 proteins (PFD0985w and PFF0200c), and a CCAAT-box DNA binding protein subunit B (PF11_0477); (2) epigenetic regulation. It is associated with PfHMGB2 (MAL8P1.72), which has a DNAbinding domain: HMG-box (High Mobility Group box). The proteins in this family have been implicated in regulation of transcription, replication, repair, and chromatin remodeling; (3) signaling. PF07_0126 is associated with at least three putative signaling proteins, including (a) 


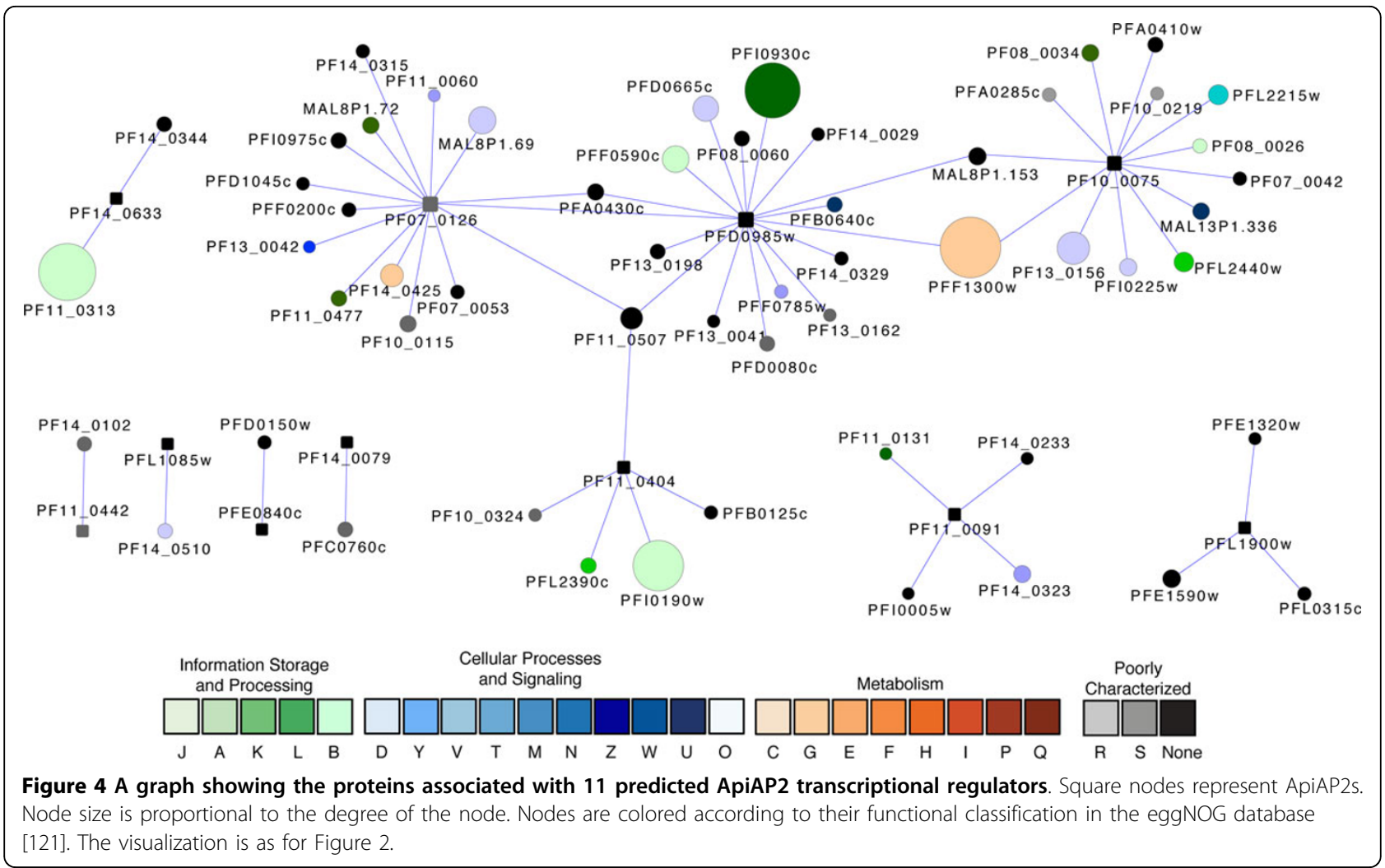

PF13_0042, which contains a forkhead-associated domain that is found in a variety of regulatory proteins involved in signaling. (b) a calcium/calmodulin-dependent protein kinase (PF11_0060) that is implicated in signaling cascades. (c) a putative 14-3-3 protein (MAL8P1.69). Proteins in 143-3 family include regulatory ligands to various signaling molecules such as kinases and receptors; (4) surface antigens for cell adhesion and entry to the host. PF07_0126 is associated with a Duffy binding-like antigen 332 (PF11_0506), an erythrocyte membrane-associated antigen (PFD1045c), and a QF122 antigen (PF10_0115) with an RNA-binding motif; (5) metabolism. The glycolytic enzyme fructose-bisphosphate aldolase (PF14_0425) is associated with the ApiAP2 protein PF07_0126.

The role of ApiAP2 proteins in transcriptional and epigenetic regulation is also indicated by a direct PPI between a putative ApiAP2 with 3 AP2 domains PF10_0075 and a histone acetyltransferase GCN5 (PF08_0034), an enzyme for histone modification and chromatin remodeling [98]. This ApiAP2 protein may also been involved in the regulation of genome integrity through a PPI with a DNA repair protein rhp16 (PFL2440w), and cytoskeleton organization of actin (Figure 4).

Two of these 11 ApiAP2 proteins have been experimentally characterized to some extent: (1) the crystal structure of the AP2 domain of PF14_0633 has been determined, revealing a multiple-site binding pattern [99], and gene disruption assays showed that its ortholog in the rodent parasite $P$. berghei was an indispensible regulator for sporozoite development in the mosquito stage [94]. However, its regulatory roles and targets remain uncharacterized in $P$. falciparum. As shown in Figure 4, it has only two direct PPIs revealed by $\mathrm{Y} 2 \mathrm{H}$ assays [57]: the first is a ribosomal protein P0, and the second protein PTEX150 (PF14_0344) is an important component in a translocon of exported proteins (PTEX). Located in the vacuole membrane, PTEX was recently discovered as a novel ATP-dependent protein trafficking machinery [100]. Notably, PTEX150 is only present in the Plasmodium genus. The PPI between PTEX150 and ApiAP2 suggests that this export machinery may have parasite-specific regulation. PTEX is becoming an attractive therapeutic target due to its importance to virulence and parasite survival and its distant evolutionary relatedness to the human host. (2) PF11_0442. Its counterpart in $P$. berghei is a transcription factor that regulates ookinetespecific gene expression for parasite invasion of the mosquito midgut. PF11_0442, however, may play a role in the red blood cell (RBC) stage: It has one PPI partner, rhoptry-associated protein 1 (RAP1, PF14_0102). RAP1 is an escort protein required to localize RAP2 to the rhoptries, apical organelles essential for RBC invasion [101].

In summary, ApiAP2 proteins are a family of stagespecific transcriptional regulators for diverse processes ranging from epigenetic modification, chromosome 
organization and dynamics, invasion, protein sorting and trafficking, protein turnover, and metabolism.

\section{Other potentially important proteins that may be involved in transcriptional regulation}

Module based subnetwork alignments predicted additional proteins that are likely involved in transcriptional regulation (Table 1). Two proteins (PFD0685c and MAL13P1.96) are members of the SMC (structural maintenance of chromosomes) superfamily; they both have a RecF/RecN/SMC N terminal domain and may be involved in chromatin cohesion and dynamics. A numbers of zinc-finger proteins were identified by network alignments as well. They exhibit different types of domain configurations, including the classical DNAbinding motif $\mathrm{C} 2 \mathrm{H} 2$ found in transcription factors, the $\mathrm{C} 3 \mathrm{HC} 4$ type (RING finger) typically found in proteins mediating ubiquitination, the $\mathrm{C}-\mathrm{x} 8-\mathrm{C}-\mathrm{x} 5-\mathrm{C}-\mathrm{x} 3-\mathrm{H}(\mathrm{CCCH})$ type implicated in cell cycle regulation, the DHHC type found in proteins important for membrane association and trafficking, the DNL type implicated in protein translocation into mitochondria, and the CW type related to DNA-binding and protein-protein interaction. A putative transcriptional coactivator (ADA2, PF10_0143) has a ZZtype zinc finger domain. ADA2 was shown, in baker's yeast and Arabidopsis thaliana, to physically interact with GCN5, a histone acetyltransferase and a potent transcriptional activator $[102,103]$. The $\mathrm{Y} 2 \mathrm{H}$ assay in $P$. falciparum [57] revealed that ADA2 has direct physical interactions with proteins including a minichromosome maintenance (MCM) complex subunit (PF14_0177), a pre-mRNA splicing factor (PFD0265w), a heat shock protein hsp70 interacting protein (PFE1370w), a sodium-dependent phosphate transporter (MAL13P1.206), a serine/threonine protein kinase in the FIKK family (PFA0130c), cathepsin C (PF11_0174), and a mature parasite-infected erythrocyte surface antigen (PFE0040c), suggesting its potential versatile roles in DNA replication, splicing, transport, protein processing, signal transduction, and invasion.

Other putative transcriptional regulators include PFE0870 and PF14_0170. PFE0870 contains two functional domains: a FACT complex subunit (SPT16/CDC68) domain which was reported to facilitate transcriptional initiation and interact with nucleosomes and histones [104], and a histone chaperone Rttp106-like domain. This protein may be involved in heterochromatin silencing and epigenetic regulation. PF14_0170 is a putative protein in the NOT global transcriptional regulator family. $\mathrm{Y} 2 \mathrm{H}$ assays showed that it had direct physical interactions with CCAAT-box DNA binding protein subunit B (PF11_0477), DNA topoisomerase II (PF14_0316), and calcium dependent protein kinase 1 (PFB0815w), emphasizing its involvement in general transcriptional control and chromosome topology and signaling processes. It also has a PPI with a
Pf11-1 protein (PF10_0374), which may play a role in protein trafficking processes associated with Maurer's cleft.

\section{Conclusions}

A functional-module based alignment approach was used to predict system components in transcriptional regulatory networks in malaria parasite $P$. falciparum. Our results predicted general transcriptional regulators that may regulate gene expression in a global or pleiotropic mode. Our results also imply a group of parasite-specific transcriptional regulators in the ApiAP2 family that play roles in diverse cellular processes ranging from chromatin remodeling, protein sorting and secretion, signal transduction, and invasion. Finally, our analysis has identified other potentially important proteins involved in transcriptional regulation. Our present knowledge of the transcriptional machinery and its regulatory capacity is rudimentary. The identification of network components in this machinery will open new avenues to the development of novel therapeutic targets and provide new insights into parasite biology, pathogenesis and virulence.

The premise of our subnetwork alignment approach is that functional annotations of the proteins can be transferred across species through conserved interactions in the aligned PPI networks. Under this framework, a priori information as to the identity or function of a gene is not necessary for the gene to be placed in a network. Thus genes identified only because of their key role in a network become potential targets. Furthermore, placement of the gene product in a systems context could, in itself, serve to identify the function of the gene product. If successfully applied, a systems biology approach circumvents the limiting factor in comparative genomics - the difficulty in obtaining reliable functional assignments.

\section{Methods}

\section{Ortholog prediction by subnetwork querying}

To predict functional orthologs for P. falciparum proteins, we formulated the problem as subnetwork querying. We first mapped the annotated $E$. coli transcriptional factors (GO:0003700: transcription factor activity) into the E. coli protein-protein interaction network. For each transcriptional factor, nearby neighbors were selected to form its neighborhood subnetwork. Similarly, each P. falciparum protein was mapped into the $P$. falciparum PPI network and a neighborhood subnetwork was built to include its nearby neighbors. Since the $E$. coli network and the $P$. falciparum network differ in size and density, the nearby neighbors were selected with a rule to control the neighborhood size. Let $N_{k}(p)$ denote the set of proteins that are exactly $k$ hops from the central protein $p$. The neighborhood of central protein $p$ is $N(p)=N_{1}(p) \cup N_{2}(p)$ $\ldots \cup N_{k}(p)$ such that $|N(p)| \leq 500$. Specifically, we first included the neighboring proteins that are 1 hop from the 
central protein. If the size of the neighborhood was less than 500 , we continued to include the proteins that were 2 hops from the central protein. We kept increasing the hop distance until the neighborhood size was larger than 500 . In other words, nearby proteins were selected by their distance to the central protein and the neighborhood size was kept below 500 unless the central protein has more than 500 direct neighbors in the PPI network.

After we obtained the neighborhood subnetwork for the E. coli transcriptional factors and all the P. falciparum proteins, we aligned each $E$. coli subnetwork against all the $P$. falciparum subnetworks. The central protein of the best-aligned P. falciparum subnetwork was identified as the functional ortholog of the E. coli transcriptional factor.

\section{Aligning neighborhood subnetworks with graph kernel}

To evaluate how well a $P$. falciparum neighborhood subnetwork aligned with an $E$. coli neighborhood subnetwork, we assigned a score for each possible alignment and summarized the alignment scores with a graph kernel. Graph kernels are effective approaches to measure the similarity between two labeled networks [105,106]. Given a pair of labeled graphs, a graph kernel is designed to summarize all possible isomorphic subgraphs (exact matches) in the two graphs. However, since there are an exponential number of subgraphs, it is computationally infeasible to detect all isomorphic subgraphs. A simplification is to compute the number of common paths between two graphs by a random walk on a product graph of the two compared graphs or by dynamic programming [107-109]. Alternatively, a graph kernel can also explicitly summarize the similarity between the shortest paths in the two graphs with each pair of shortest paths measured by a convolution kernel [110]. Since our focus is only on the paths that go through the central protein, we modified the shortest path graph kernel to only consider the paths between the central protein and the other proteins in the subnetwork. The underlying hypothesis is that each shortest path going through the central protein can characterize the functional role of the protein in the chained molecular activities along the path. As shown in Figure 5, given two subnetworks $S_{p}$ with central protein $p$ and $S_{q}$ with central protein $q$, we define a simple shortest path similarity function,

$$
K\left(S_{q}, S_{p}\right)=\frac{1}{\left|S_{q}\right|+\left|S_{p}\right|} \prod_{\forall(i 1, i 2) \in S_{q}} B\left((i 1, i 2), S_{p}\right)
$$

where,

$$
\begin{gathered}
B\left((i 1, i 2), S_{p}\right)=\max _{\forall(j 1, j 2) \in S_{p}} \frac{2 E(i 1, j 1) E(i 2, j 2)}{\operatorname{dist}(i 1, i 2)+\operatorname{dist}(j 1, j 2)} \\
E(x, y)=\exp \left(-\frac{\operatorname{Eval}(x, y)}{\sigma}\right) \text { with the normalization para- }
\end{gathered}
$$
meter $\sigma=10$ measures the sequence similarity between proteins $x$ and $y$ based on the E-value of the sequence alignment, and $\operatorname{dist}(x, y)$ is the length of the shortest path connecting proteins $x$ and $y$ in the PPI subnetwork. Since the scores were small numbers, the computation was done in - $\log _{10}$ scale. In this similarity function, we took each pair of the proteins (i1, i2) in one subnetwork and identify the $(\mathrm{j} 1, \mathrm{j} 2)$ in the other subnetwork that gives the maximum ratio between their sequence similarity with respect to $(i 1$,

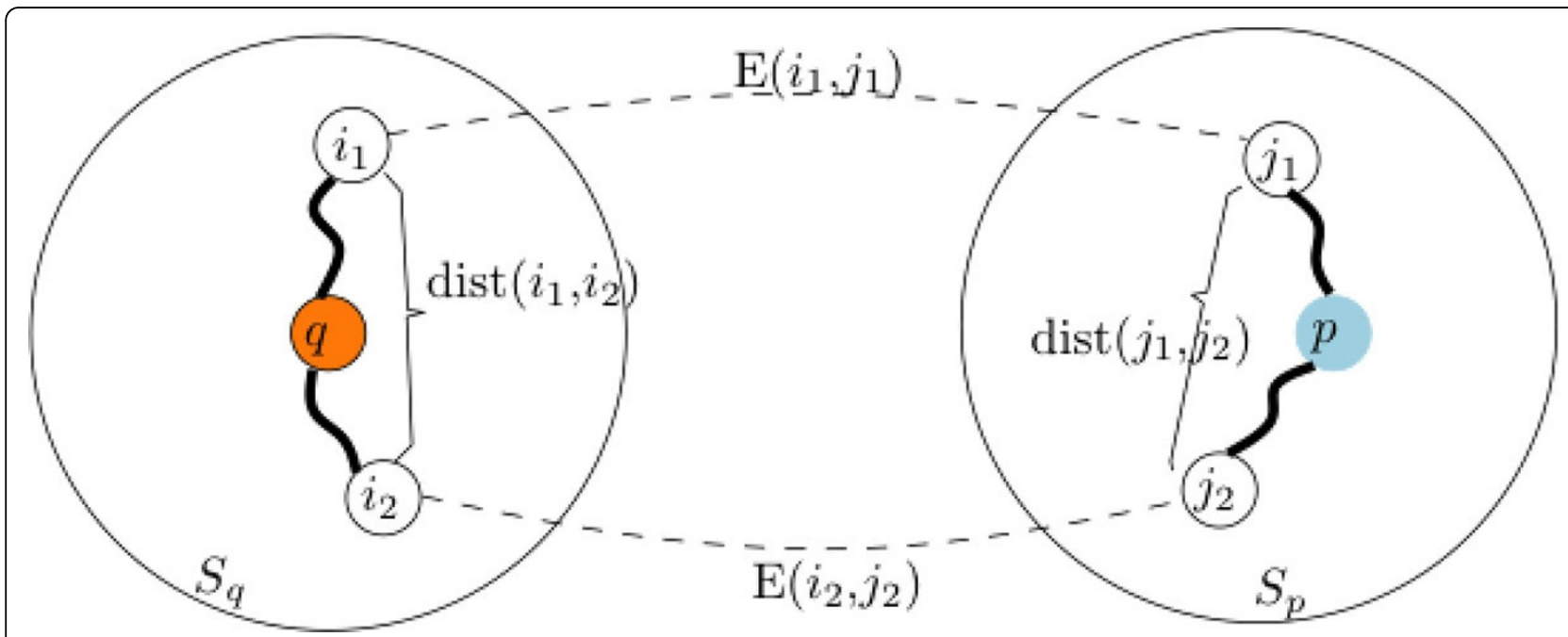

Figure 5 Computation of subnetwork alignment score. The alignment score between subnetwork $S_{p}$ and $S_{q}$ is the summation of the similarity score between all pairs of matched shortest paths $((\mathrm{i} 1, \mathrm{i} 2)$ and $(\mathrm{j} 1, \mathrm{j} 2)$ in the figure), calculated based on the sequence similarities (E(i1, j1) and $E(i 2, j 2))$ and the distances in the subnetworks (dist(i1, i2) and dist(j1, j2)). 
i2) and the closeness in the subnetworks. Specifically, we computed the shortest path through the central protein between all pairs of proteins in the neighborhood subnetwork. The shortest paths of two neighborhood subnetworks are then compared and scored pairwise. The total of the alignment scores was reported as the subnetwork alignment score. Our strategy is to incorporate both the sequence similarity of the proteins and the role of the central proteins in the subnetwork in the similarity measure, which summarizes the functional coherence between the two subnetworks and between the two central proteins of the two subnetworks.

\section{Network data and analysis}

The E. coli protein-protein interactions were obtained from IntAct database. IntAct database provides binary protein-protein interactions derived from literature curation or direct user submissions. The complete set of proteinprotein associations for P. falciparum was extracted from the STRING database [111]; each association between a pair of proteins has a confidence score $(\mathrm{S})$ ranging from 0.15 to 0.999 , based on the evidence from sequence similarity comparison, pathway (KEGG [112] and PlasmoCyc [52]) assignments, genome neighborhood analysis, phylogenetic inference, and literature co-occurrence. The associations were visualized in Cytoscape [113] and converted to an undirected weighted graph, where there is a single edge between any pair of proteins and the $S$ value is used as the weight. The network was characterized using NetworkAnalyzer [114]. The default values were used for all three plugins. The set of proteins associated with transcriptional regulation were screened using BiNGO [115] to determine if any categories of proteins, as identified by their Gene Ontology terms, were enriched. The hypergeometric test was used with the Benjamini and Hochberg false discovery date correction. A significance level of 0.05 was selected.

\section{The omics data mining}

P. falciparum genomic sequence and annotation data [5], transcriptomic microarray data $[7,9,12]$, mass-spectrometry proteomic data $[34,35,39,40]$, and protein-protein interactome [57] data for network associated proteins were downloaded from PlasmoDB (http://www.plasmodb.org) [116]. Conserved domains/motifs were identified by searching InterPro [117]. Multiple alignments were obtained using the ClustalX program [118] and Tcoffee [119], followed by manual inspection and editing. Phylogenetic trees were inferred by the neighbor-joining method implemented in MEGA5 [120]. Bootstrap resampling with 1,000 replicates was carried out to assess support for individual branches. Bootstrap values of $<50 \%$ were collapsed and treated as polytomies.

\section{Additional material}

Additional file 1: Functional orthologs involved in transcriptional regulation in $P$. falciparum. The query genome is $P$. falciparum, and the target genome is E. coli. GO: Gene Ontology. BP: Biological Process. MF: Molecular Function. CC: Cellular Component.

Additional file 2: The protein-protein associations involving 11 ApiAP2 transcriptional regulators in $P$. falciparum.

\section{List of abbreviations used}

EBA: erythrocyte binding antigen; DBL: Duffy binding-like; GO: Gene Ontology; HMG: High Mobility Group; HSP: heat shock protein; MCM: minichromosome maintenance; MSP: merozoite surface protein; MRF: Markov Random Field; ORF: open reading frame; PPI: protein-protein interaction; RAP: rhoptry-associated protein; RBC: red blood cell; SMC: structural maintenance of chromosomes; SVM: support vector machine; $\mathrm{Y} 2 \mathrm{H}$ : yeast 2-hybrid.

\section{Acknowledgements}

We thank PlasmoDB for providing access to malaria omic data. This work is supported by NIH grants GM100806, GM081068 and Al080579 to YW. YW is also supported by NIH grant RR013646. KR and CH are supported by University of Minnesota Grant-in-Aid of Research, Artistry and Scholarship. This work received computational support from Computational System Biology Core, funded by the National Institute on Minority Health and Health Disparities (G12MD007591) from the National Institutes of Health. The content is solely the responsibility of the authors and does not necessarily represent the official views of the National Institute of General Medical Sciences, National Institute of Allergy and Infectious Diseases, National Center for Research Resources, or the National Institutes of Health. This article has been published as part of BMC Systems Biology Volume 6 Supplement 3, 2012: Proceedings of The International Conference on Intelligent Biology and Medicine (ICIBM) - Systems Biology. The full contents of the supplement are available online at http://www.biomedcentral.com/ bmcsystbiol/supplements/6/S3.

\section{Author details}

${ }^{1}$ Department of Biology, University of Texas at San Antonio, San Antonio, TX 78249, USA. ²Department of Computer Science and Engineering, University of Minnesota Twin Cities, Minneapolis, MN 55455, USA. ${ }^{3}$ Department of Biology, College of Staten Island, City University of New York, Staten Island, NY 10314, USA. ${ }^{4}$ Department of Bacteriology, American Type Culture Collection, Manassas, VA 20110, USA. ${ }^{5}$ South Texas Center for Emerging Infectious Diseases, University of Texas at San Antonio, San Antonio, TX 78249, USA.

\section{Authors' contributions}

YW and RK conceived and designed the study. All authors performed bioinformatics data analysis and drafted the manuscript. All authors read and approved the final manuscript.

\section{Competing interests}

The authors declare that they have no competing interests.

Published: 17 December 2012

\section{References}

1. Carlton J: The Plasmodium vivax genome sequencing project. Trends Parasitol 2003, 19(5):227-231.

2. Carlton J, Silva J, Hall N: The genome of model malaria parasites, and comparative genomics. Curr Issues Mol Biol 2005, 7(1):23-37.

3. Carlton JM, Adams JH, Silva JC, Bidwell SL, Lorenzi H, Caler E, Crabtree J, Angiuoli SV, Merino EF, Amedeo P, et al: Comparative genomics of the neglected human malaria parasite Plasmodium vivax. Nature 2008, 455(7214):757-763.

4. Carlton JM, Angiuoli SV, Suh BB, Kooij TW, Pertea M, Silva JC, Ermolaeva MD, Allen JE, Selengut JD, Koo HL, et al: Genome sequence and 
comparative analysis of the model rodent malaria parasite Plasmodium yoelii yoelii. Nature 2002, 419(6906):512-519.

5. Gardner MJ, Hall N, Fung E, White O, Berriman M, Hyman RW, Carlton JM, Pain A, Nelson KE, Bowman $S$, et al: Genome sequence of the human malaria parasite Plasmodium falciparum. Nature 2002, 419(6906):498-511.

6. Pain A, Bohme U, Berry AE, Mungall K, Finn RD, Jackson AP, Mourier T, Mistry J, Pasini EM, Aslett MA, et al: The genome of the simian and human malaria parasite Plasmodium knowlesi. Nature 2008, 455(7214):799-803.

7. Bozdech Z, Llinas M, Pulliam BL, Wong ED, Zhu J, DeRisi JL: The Transcriptome of the Intraerythrocytic Developmental Cycle of Plasmodium falciparum. PLOS Biol 2003, 1(1):E5.

8. Bozdech Z, Mok S, Hu G, Imwong M, Jaidee A, Russell B, Ginsburg H, Nosten F, Day NP, White NJ, et al: The transcriptome of Plasmodium vivax reveals divergence and diversity of transcriptional regulation in malaria parasites. Proc Natl Acad Sci USA 2008, 105(42):16290-16295.

9. Bozdech Z, Zhu J, Joachimiak MP, Cohen FE, Pulliam B, DeRisi JL: Expression profiling of the schizont and trophozoite stages of Plasmodium falciparum with a long-oligonucleotide microarray. Genome Biol 2003, 4(2):R9.

10. Hayward RE, DeRisi UL, Alfadhli S, Kaslow DC, Brown PO, Rathod PK: Shotgun DNA microarrays and stage-specific gene expression in Plasmodium falciparum malaria. Molecular Microbiology 2000, 35(1):6-14.

11. Le Roch KG, Zhou Y, Batalov S, Winzeler EA: Monitoring the chromosome 2 intraerythrocytic transcriptome of Plasmodium falciparum using oligonucleotide arrays. Am J Trop Med Hyg 2002, 67(3):233-243.

12. Le Roch KG, Zhou Y, Blair PL, Grainger M, Moch JK, Haynes JD, De La Vega P, Holder AA, Batalov S, Carucci DJ, et al: Discovery of gene function by expression profiling of the malaria parasite life cycle. Science 2003, 301(5639):1503-1508.

13. Llinas M, Bozdech Z, Wong ED, Adai AT, DeRisi JL: Comparative whole genome transcriptome analysis of three Plasmodium falciparum strains. Nucleic Acids Res 2006, 34(4):1166-1173.

14. Mamoun CB, Gluzman IY, Hott C, MacMillan SK, Amarakone AS, Anderson DL, Carlton JMR, Dame JB, Chakrabarti D, Martin RK, et al: Coordinated programme of gene expression during asexual intraerythrocytic development of the human malaria parasite Plasmodium falciparum revealed by microarray analysis. Molecular Microbiology 2001, 39(1):26-36.

15. Tarun AS, Peng X, Dumpit RF, Ogata Y, Silva-Rivera H, Camargo N, Daly TM, Bergman LW, Kappe SH: A combined transcriptome and proteome survey of malaria parasite liver stages. Proc Natl Acad Sci USA 2008, 105(1):305-310.

16. Crameri A, Marfurt J, Mugittu K, Maire N, Regos A, Coppee JY, Sismeiro O, Burki R, Huber E, Laubscher D, et al: Rapid microarray-based method for monitoring of all currently known single-nucleotide polymorphisms associated with parasite resistance to antimalaria drugs. I Clin Microbiol 2007, 45(11):3685-3691.

17. Cui L, Miao J, Furuya T, Li X, Su XZ, Cui L: PfGCN5-mediated histone H3 acetylation plays a key role in gene expression in Plasmodium falciparum. Eukaryot Cell 2007, 6(7):1219-1227.

18. Ralph SA, Bischoff E, Mattei D, Sismeiro O, Dillies MA, Guigon G, Coppee JY, David PH, Scherf A: Transcriptome analysis of antigenic variation in Plasmodium falciparum-var silencing is not dependent on antisense RNA. Genome Biol 2005, 6(11):R93.

19. Samarakoon U, Gonzales JM, Patel JJ, Tan A, Checkley L, Ferdig MT: The landscape of inherited and de novo copy number variants in a Plasmodium falciparum genetic cross. BMC Genomics 2011, 12:457.

20. Ballif M, Hii J, Marfurt J, Crameri A, Fafale A, Felger I, Beck HP, Genton B: Monitoring of malaria parasite resistance to chloroquine and sulphadoxine-pyrimethamine in the Solomon Islands by DNA microarray technology. Malar J 2010, 9:270.

21. Dharia NV, Sidhu AB, Cassera MB, Westenberger SJ, Bopp SE, Eastman RT, Plouffe D, Batalov S, Park DJ, Volkman SK, et al: Use of high-density tiling microarrays to identify mutations globally and elucidate mechanisms of drug resistance in Plasmodium falciparum. Genome Biol 2009, 10(2):R21.

22. Ganesan K, Ponmee N, Jiang L, Fowble JW, White J, Kamchonwongpaisan S, Yuthavong Y, Wilairat P, Rathod PK: A genetically hard-wired metabolic transcriptome in Plasmodium falciparum fails to mount protective responses to lethal antifolates. PLoS Pathog 2008, 4(11):e1000214.
23. Jiang HY, Yi M, Mu JB, Zhang L, Ivens A, Klimczak LJ, Huyen Y, Stephens RM, Su XZ: Detection of genome-wide polymorphisms in the AT-rich Plasmodium falciparum genome using a high-density microarray. Bmc Genomics 2008, 9.

24. Zhang GQ, Guan YY, Sheng HH, Zheng B, Wu S, Xiao HS, Tang LH: Multiplex PCR and oligonucleotide microarray for detection of singlenucleotide polymorphisms associated with Plasmodium falciparum drug resistance. J Clin Microbiol 2008, 46(7):2167-2174.

25. Daily JP, Le Roch KG, Sarr O, Fang X, Zhou Y, Ndir O, Mboup S, Sultan A, Winzeler EA, Wirth DF: In vivo transcriptional profiling of Plasmodium falciparum. Malar J 2004, 3(1):30.

26. Daily JP, Le Roch KG, Sarr O, Ndiaye D, Lukens A, Zhou Y, Ndir O, Mboup S, Sultan A, Winzeler EA, et al: In vivo transcriptome of Plasmodium falciparum reveals overexpression of transcripts that encode surface proteins. J Infect Dis 2005, 191(7):1196-1203.

27. Young JA, Fivelman QL, Blair PL, de la Vega $P$, Le Roch $K G$, Zhou $Y$, Carucci DJ, Baker DA, Winzeler EA: The Plasmodium falciparum sexual development transcriptome: a microarray analysis using ontology-based pattern identification. Mol Biochem Parasitol 2005, 143(1):67-79.

28. Claessens A, Ghumra A, Gupta AP, Mok S, Bozdech Z, Rowe JA: Design of a variant surface antigen-supplemented microarray chip for whole transcriptome analysis of multiple Plasmodium falciparum cytoadherent strains, and identification of strain-transcendent rif and stevor genes. Malar J 2011, 10(1):180.

29. Tan JC, Miller BA, Tan A, Patel JJ, Cheeseman IH, Anderson TJ, Manske M, Maslen G, Kwiatkowski DP, Ferdig MT: An optimized microarray platform for assaying genomic variation in Plasmodium falciparum field populations. Genome Biol 2011, 12(4):R35.

30. Broadbent KM, Park D, Wolf AR, Van Tyne D, Sims JS, Ribacke U, Volkman S, Duraisingh $M$, Wirth D, Sabeti PC, et al: A global transcriptional analysis of Plasmodium falciparum malaria reveals a novel family of telomereassociated IncRNAs. Genome Biol 2011, 12(6):R56.

31. Chen JH, Jung JW, Wang Y, Ha KS, Lu F, Lim CS, Takeo S, Tsuboi T, Han ET: Immunoproteomics profiling of blood stage Plasmodium vivax infection by high-throughput screening assays. J Proteome Res 2010, 9(12):6479-6489.

32. Cooper RA, Carucci DJ: Proteomic approaches to studying drug targets and resistance in Plasmodium. Curr Drug Targets Infect Disord 2004, 4(1):41-51

33. Doolan DL, Southwood S, Freilich DA, Sidney J, Graber NL, Shatney L, Bebris L, Florens L, Dobano C, Witney AA, et al: Identification of Plasmodium falciparum antigens by antigenic analysis of genomic and proteomic data. Proceedings of the National Academy of Sciences of the United States of America 2003, 100(17):9952-9957.

34. Florens L, Liu X, Wang YF, Yang SG, Schwartz O, Peglar M, Carucci DJ, Yates JR, WU YM: Proteomics approach reveals novel proteins on the surface of malaria-infected erythrocytes. Mol Biochem Parasit 2004, 135(1):1-11.

35. Florens $L$, Washburn MP, Raine JD, Anthony RM, Grainger M, Haynes JD, Moch JK, Muster N, Sacci JB, Tabb DL, et al: A proteomic view of the Plasmodium falciparum life cycle. Nature 2002, 419(6906):520-526.

36. Fried M, Wendler JP, Mutabingwa TK, Duffy PE: Mass spectrometric analysis of Plasmodium falciparum erythrocyte membrane protein-1 variants expressed by placental malaria parasites. Proteomics 2004, 4(4):1086-1093.

37. Gelhaus C, Fritsch J, Krause E, Leippe M: Fractionation and identification of proteins by 2-DE and MS: towards a proteomic analysis of Plasmodium falciparum. Proteomics 2005, 5(16):4213-4222.

38. Lal K, Prieto JH, Bromley E, Sanderson SJ, Yates JR, Wastling JM, Tomley FM, Sinden RE: Characterisation of Plasmodium invasive organelles; an ookinete microneme proteome. Proteomics 2009, 9(5):1142-1151.

39. Lasonder E, Ishihama Y, Andersen JS, Vermunt AMW, Pain A, Sauerwein RW, Eling WMC, Hall N, Waters AP, Stunnenberg HG, et al: Analysis of the Plasmodium falciparum proteome by high-accuracy mass spectrometry. Nature 2002, 419(6906):537-542.

40. Lasonder E, Janse CJ, van Gemert GJ, Mair GR, Vermunt AM, Douradinha BG, van Noort V, Huynen MA, Luty AJ, Kroeze $H$, et al: Proteomic profiling of Plasmodium sporozoite maturation identifies new proteins essential for parasite development and infectivity. PLoS Pathog 2008, 4(10):e1000195. 
41. Nirmalan N, Sims PF, Hyde JE: Quantitative proteomics of the human malaria parasite Plasmodium falciparum and its application to studies of development and inhibition. Mol Microbiol 2004, 52(4):1187-1199.

42. Patra KP, Johnson JR, Cantin GT, Yates JR, Vinetz JM: Proteomic analysis of zygote and ookinete stages of the avian malaria parasite Plasmodium gallinaceum delineates the homologous proteomes of the lethal human malaria parasite Plasmodium falciparum. Proteomics 2008, 8(12):2492-2499.

43. Prieto JH, Koncarevic S, Park SK, Yates J, Becker K: Large-scale differential proteome analysis in Plasmodium falciparum under drug treatment. PLoS One 2008, 3(12):e4098.

44. Sam-Yellowe TY, Florens L, Johnson JR, Wang T, Drazba JA, Le Roch KG, Zhou Y, Batalov S, Carucci DJ, Winzeler EA, et al: A Plasmodium gene family encoding Maurer's cleft membrane proteins: structural properties and expression profiling. Genome Res 2004, 14(6):1052-1059.

45. Sam-Yellowe TY, Florens L, Wang TM, Raine JD, Carucci DJ, Sinden R, Yates JR: Proteome analysis of rhoptry-enriched fractions isolated from Plasmodium merozoites. Journal of Proteome Research 2004, 3(5):995-1001.

46. Koncarevic S, Bogumil R, Becker K: SELDI-TOF-MS analysis of chloroquine resistant and sensitive Plasmodium falciparum strains. Proteomics 2007, 7(5):711-721.

47. Clark K, Niemand J, Reeksting S, Smit S, van Brummelen AC, Williams M, Louw Al, Birkholtz L: Functional consequences of perturbing polyamine metabolism in the malaria parasite, Plasmodium falciparum. Amino Acids 2010, 38(2):633-644.

48. Ginsburg $\mathrm{H}$ : Progress in in silico functional genomics: the malaria Metabolic Pathways database. Trends Parasitol 2006, 22(6):238-240.

49. Ginsburg $H$, Tilley L: Plasmodium falciparum metabolic pathways (MPMP) project upgraded with a database of subcellular locations of gene products. Trends Parasitol 2011.

50. Lakshmanan V, Rhee KY, Daily JP: Metabolomics and malaria biology. Mol Biochem Parasitol 2011, 175(2):104-111.

51. Plata G, Hsiao TL, Olszewski KL, Llinas M, Vitkup D: Reconstruction and flux-balance analysis of the Plasmodium falciparum metabolic network. Mol Syst Biol 2010, 6:408.

52. Yeh I, Hanekamp T, Tsoka S, Karp PD, Altman RB: Computational analysis of Plasmodium falciparum metabolism: organizing genomic information to facilitate drug discovery. Genome Res 2004, 14(5):917-924.

53. Lian LY, Al-Helal M, Roslaini AM, Fisher N, Bray PG, Ward SA, Biagini GA: Glycerol: an unexpected major metabolite of energy metabolism by the human malaria parasite. Malar J 2009, 8:38.

54. Schwarzer E, Kuhn $H$, Valente E, Arese P: Malaria-parasitized erythrocytes and hemozoin nonenzymatically generate large amounts of hydroxy fatty acids that inhibit monocyte functions. Blood 2003, 101(2):722-728.

55. Date SV, Stoeckert CJ Jr: Computational modeling of the Plasmodium falciparum interactome reveals protein function on a genome-wide scale. Genome Res 2006, 16(4):542-549.

56. LaCount DJ, Schoenfeld LW, Fields S: Selection of yeast strains with enhanced expression of Plasmodium falciparum proteins. Mol Biochem Parasitol 2009, 163(2):119-122.

57. LaCount DJ, Vignali M, Chettier R, Phansalkar A, Bell R, Hesselberth JR, Schoenfeld LW, Ota I, Sahasrabudhe S, Kurschner C, et al: A protein interaction network of the malaria parasite Plasmodium falciparum. Nature 2005, 438(7064):103-107.

58. Mitrofanova A, Kleinberg S, Carlton J, Kasif S, Mishra B: Predicting malaria interactome classifications from time-course transcriptomic data along the intraerythrocytic developmental cycle. Artif Intell Med 2010, 49(3):167-176.

59. Suthram $\mathrm{S}$, Sittler $\mathrm{T}$, Ideker $\mathrm{T}$ : The Plasmodium protein network diverges from those of other eukaryotes. Nature 2005, 438(7064):108-112.

60. Hall N, Karras M, Raine JD, Carlton JM, Kooij TW, Berriman M, Florens L, Janssen CS, Pain A, Christophides GK, et al: A comprehensive survey of the Plasmodium life cycle by genomic, transcriptomic, and proteomic analyses. Science 2005, 307(5706):82-86.

61. Samarakoon U, Regier A, Tan A, Desany BA, Collins B, Tan JC, Emrich SJ, Ferdig MT: High-throughput 454 resequencing for allele discovery and recombination mapping in Plasmodium falciparum. BMC Genomics 2011, 12:116.

62. Vignali M, Armour CD, Chen J, Morrison R, Castle JC, Biery MC, Bouzek H, Moon W, Babak T, Fried M, et al: NSR-seq transcriptional profiling enables identification of a gene signature of Plasmodium falciparum parasites infecting children. J Clin Invest 2011, 121(3):1119-1129.

63. Otto TD, Wilinski D, Assefa S, Keane TM, Sarry LR, Bohme U, Lemieux J, Barrell B, Pain A, Berriman M, et al: New insights into the blood-stage transcriptome of Plasmodium falciparum using RNA-Seq. Mol Microbiol 2010, 76(1):12-24.

64. Bruckner S, Huffner F, Karp RM, Shamir R, Sharan R: TORQUE: topology-free querying of protein interaction networks. Nucleic Acids Res 2009, 37(Web Server):W106-108.

65. Flannick J, Novak A, Do CB, Srinivasan BS, Batzoglou S: Automatic parameter learning for multiple local network alignment. J Comput Biol 2009, 16(8):1001-1022.

66. Kelley BP, Yuan B, Lewitter F, Sharan R, Stockwell BR, Ideker T: PathBLAST: a tool for alignment of protein interaction networks. Nucleic Acids Res 2004, 32(Web Server):W83-88.

67. Koyuturk M, Kim Y, Subramaniam S, Szpankowski W, Grama A: Detecting conserved interaction patterns in biological networks. J Comput Biol 2006, 13(7):1299-1322.

68. Koyuturk M, Kim Y, Topkara U, Subramaniam S, Szpankowski W, Grama A: Pairwise alignment of protein interaction networks. J Comput Biol 2006, 13(2):182-199.

69. Sharan R, Suthram S, Kelley RM, Kuhn T, McCuine S, Uetz P, Sittler T, Karp RM, Ideker T: Conserved patterns of protein interaction in multiple species. Proc Natl Acad Sci USA 2005, 102(6):1974-1979.

70. Kuang R, le E, Wang K, Wang K, Siddiqi M, Freund Y, Leslie C: Profile-based string kernels for remote homology detection and motif extraction. J Bioinform Comput Biol 2005, 3(3):527-550.

71. Kuang R, Gu J, Cai H, Wang Y: Improved prediction of malaria degradomes by supervised learning with SVM and profile kernel. Genetica 2009, 136(1):189-209.

72. Lilburn TG, Cai H, Zhou Z, Wang Y: Protease-associated Cellular Networks in Malaria Parasite Plasmodium falciparum. BMC Genomics 2011, 12(Suppl 5):S9.

73. Bandyopadhyay S, Sharan R, Ideker T: Systematic identification of functional orthologs based on protein network comparison. Genome Res 2006, 16(3):428-435.

74. Zaslavskiy M, Bach F, Vert JP: Global alignment of protein-protein interaction networks by graph matching methods. Bioinformatics 2009, 25(12):i259-267.

75. Klau GW: A new graph-based method for pairwise global network alignment. BMC Bioinformatics 2009, 10 Suppl 1:S59.

76. Zhenping L, Zhang S, Wang Y, Zhang XS, Chen L: Alignment of molecular networks by integer quadratic programming. Bioinformatics 2007, 23(13):1631-1639.

77. Singh $R, X u J$, Berger B: Global alignment of multiple protein interaction networks. Pac Symp Biocomput 2008, 303-314.

78. Boutte CC, Srinivasan BS, Flannick JA, Novak AF, Martens AT, Batzoglou S, Viollier PH, Crosson S: Genetic and computational identification of a conserved bacterial metabolic module. PLoS Genet 2008, 4(12):e1000310.

79. Cui L, Miao J: Chromatin-mediated epigenetic regulation in the malaria parasite Plasmodium falciparum. Eukaryot Cell 2010, 9(8):1138-1149.

80. Salcedo-Amaya AM, van Driel MA, Alako BT, Trelle MB, van den Elzen AM, Cohen AM, Janssen-Megens EM, van de Vegte-Bolmer M, Selzer RR, Iniguez $\mathrm{AL}$, et al: Dynamic histone $\mathrm{H} 3$ epigenome marking during the intraerythrocytic cycle of Plasmodium falciparum. Proc Natl Acad Sci USA 2009, 106(24):9655-9660.

81. Buendia-Orozco J, Guerrero A, Pastor N: Model of the TBP-TFIIB complex from Plasmodium falciparum: interface analysis and perspectives as a new target for antimalarial design. Arch Med Res 2005, 36(4):317-330.

82. Militello KT, Dodge M, Bethke L, Wirth DF: Identification of regulatory elements in the Plasmodium falciparum genome. Mol Biochem Parasit 2004, 134(1):75-88.

83. Young JA, Johnson JR, Benner C, Yan SF, Chen K, Le Roch KG, Zhou Y, Winzeler EA: In silico discovery of transcription regulatory elements in Plasmodium falciparum. BMC Genomics 2008, 9:70.

84. Coulson RMR, Hall N, Ouzounis CA: Comparative genomics of transcriptional control in the human malaria parasite Plasmodium falciparum. Genome Research 2004, 14(8):1548-1554.

85. Bischoff $E$, Vaquero C: In silico and biological survey of transcriptionassociated proteins implicated in the transcriptional machinery during 
the erythrocytic development of Plasmodium falciparum. BMC Genomics 2010, 11:34

86. Florent I, Marechal E, Gascuel O, Brehelin L: Bioinformatic strategies to provide functional clues to the unknown genes in Plasmodium falciparum genome. Parasite 2010, 17(4):273-283.

87. Huang da W, Sherman BT, Lempicki RA: Systematic and integrative analysis of large gene lists using DAVID bioinformatics resources. Nat Protoc 2009, 4(1):44-57.

88. Maillet L, Collart MA: Interaction between Not1p, a component of the Ccr4-not complex, a global regulator of transcription, and Dhh1p, a putative RNA helicase. J Biol Chem 2002, 277(4):2835-2842.

89. Tewari R, Ogun SA, Gunaratne RS, Crisanti A, Holder AA: Disruption of Plasmodium berghei merozoite surface protein 7 gene modulates parasite growth in vivo. Blood 2005, 105(1):394-396.

90. Riechmann $\mathrm{L}$, Meyerowitz EM: The AP2/EREBP family of plant transcription factors. Biol Chem 1998, 379(6):633-646.

91. Balaji S, Babu MM, lyer LM, Aravind L: Discovery of the principal specific transcription factors of Apicomplexa and their implication for the evolution of the AP2-integrase DNA binding domains. Nucleic Acids Res 2005, 33(13):3994-4006.

92. Flueck C, Bartfai R, Niederwieser I, Witmer K, Alako BT, Moes S, Bozdech Z, Jenoe $P$, Stunnenberg HG, Voss TS: A major role for the Plasmodium falciparum ApiAP2 protein PfSIP2 in chromosome end biology. PLOS Pathog 2010, 6(2):e1000784.

93. Painter HJ, Campbell TL, Llinas M: The Apicomplexan AP2 family: integral factors regulating Plasmodium development. Mol Biochem Parasitol 2011, 176(1):1-7.

94. Yuda M, Iwanaga S, Shigenobu S, Kato T, Kaneko I: Transcription factor AP2-Sp and its target genes in malarial sporozoites. Mol Microbiol 2010, 75(4):854-863.

95. Yuda M, Iwanaga S, Shigenobu S, Mair GR, Janse CJ, Waters AP, Kato T, Kaneko I: Identification of a transcription factor in the mosquito-invasive stage of malaria parasites. Mol Microbiol 2009, 71(6):1402-1414.

96. Cowman AF, Crabb BS: Invasion of red blood cells by malaria parasites. Cell 2006, 124(4):755-766.

97. Lanzer M, Wickert H, Krohne G, Vincensini L, Braun Breton C: Maurer's clefts: a novel multi-functional organelle in the cytoplasm of Plasmodium falciparum-infected erythrocytes. Int J Parasitol 2006, 36(1):23-36.

98. Bougdour A, Braun L, Cannella D, Hakimi MA: Chromatin modifications: implications in the regulation of gene expression in Toxoplasma gondii. Cell Microbiol 2010, 12(4):413-423.

99. Lindner SE, De Silva EK, Keck JL, Llinas M: Structural determinants of DNA binding by a P. falciparum ApiAP2 transcriptional regulator. J Mol Biol 2010, 395(3):558-567.

100. de Koning-Ward TF, Gilson PR, Boddey JA, Rug M, Smith BJ, Papenfuss AT, Sanders PR, Lundie RJ, Maier AG, Cowman AF, et al: A newly discovered protein export machine in malaria parasites. Nature 2009, 459(7249):945-949.

101. Baldi DL, Andrews KT, Waller RF, Roos DS, Howard RF, Crabb BS, Cowman AF: RAP1 controls rhoptry targeting of RAP2 in the malaria parasite Plasmodium falciparum. Embo J 2000, 19(11):2435-2443.

102. Mao Y, Pavangadkar KA, Thomashow MF, Triezenberg SJ: Physical and functional interactions of Arabidopsis ADA2 transcriptional coactivator proteins with the acetyltransferase GCN5 and with the cold-induced transcription factor CBF1. Biochim Biophys Acta 2006, 1759(1-2):69-79.

103. Marcus GA, Silverman N, Berger SL, Horiuchi J, Guarente L: Functional similarity and physical association between GCN5 and ADA2: putative transcriptional adaptors. Embo J 1994, 13(20):4807-4815

104. Orphanides G, Wu WH, Lane WS, Hampsey M, Reinberg D: The chromatinspecific transcription elongation factor FACT comprises human SPT16 and SSRP1 proteins. Nature 1999, 400(6741):284-288.

105. Kashima $H$, Inokuchi A: Kernels for graphs. In Kernel methods in computational biology. The MIT Press;Schölkopf B, Tsuda K, Vert JP 2004:155-170.

106. Vishwanathan SVN, Schraudolph NN, Kondor R, Borgwardt KM: Graph Kernels. Journal of Machine Learning Research 2010, 11:1201-1242.

107. Gartner T, Flach P, Wrobel S: On graph kernels: Hardness results and efficient alternatives. Learning Theory and Kernel Machines 2003, 2777:129-143.
108. Kashima H, Inokuchi A: Kernels for graph classification. The 2002 IEEE International Conference on Data Mining (ICDM 2002) 2002, 31-36.

109. Kashima H, Tsuda K, Inokuchi A: Marginalized kernels between labeled graphs. Proc of the Twentieth International Conference on Machine Learning (ICML 2003) 2003, 321-328.

110. Borgwardt KM, Kriegel HP, Vishwanathan SV, Schraudolph NN: Graph kernels for disease outcome prediction from protein-protein interaction networks. Pac Symp Biocomput 2007, 4-15.

111. Szklarczyk D, Franceschini A, Kuhn M, Simonovic M, Roth A, Minquez $P$, Doerks T, Stark M, Muller J, Bork P, et al: The STRING database in 2011: functional interaction networks of proteins, globally integrated and scored. Nucleic Acids Res 2010, 39(Database):D561-568.

112. Kanehisa M, Goto S, Furumichi M, Tanabe M, Hirakawa M: KEGG for representation and analysis of molecular networks involving diseases and drugs. Nucleic Acids Res 2010, 38(Database):D355-360.

113. Smoot ME, Ono K, Ruscheinski J, Wang PL, Ideker T: Cytoscape 2.8: new features for data integration and network visualization. Bioinformatics 2010, 27(3):431-432.

114. Assenov Y, Ramirez F, Schelhorn SE, Lengauer T, Albrecht M: Computing topological parameters of biological networks. Bioinformatics 2008, 24(2):282-284

115. Maere S, Heymans K, Kuiper M: BiNGO: a Cytoscape plugin to assess overrepresentation of gene ontology categories in biological networks. Bioinformatics 2005, 21(16):3448-3449.

116. Aurrecoechea C, Brestelli J, Brunk BP, Dommer J, Fischer S, Gajiia B, Gao X Gingle A, Grant G, Harb OS, et al: PlasmoDB: a functional genomic database for malaria parasites. Nucleic Acids Res 2009, 37(Database) D539-543.

117. Hunter S, Apweiler R, Attwood TK, Bairoch A, Bateman A, Binns D, Bork P, Das U, Daugherty L, Duquenne L, et al: InterPro: the integrative protein signature database. Nucleic Acids Research 2009, 37:D211-D215.

118. Jeanmougin F, Thompson JD, Gouy M, Higgins DG, Gibson TJ: Multiple sequence alignment with Clustal $\mathrm{x}$. Trends in Biochemical Sciences 1998, 23(10):403-405.

119. Notredame C, Higgins DG, Heringa J: T-Coffee: a novel method for fast and accurate multiple sequence alignment. J Mol Biol 2000, 302(1):205-217.

120. Tamura K, Peterson D, Peterson N, Stecher G, Nei M, Kumar S: MEGA5: Molecular Evolutionary Genetics Analysis using Maximum Likelihood, Evolutionary Distance, and Maximum Parsimony Methods. Mol Biol Evol 2011.

121. Muller J, Szklarczyk D, Julien P, Letunic I, Roth A, Kuhn M, Powell S, von Mering $C$, Doerks $T$, Jensen $L$, et al: eggNOG v2.0: extending the evolutionary genealogy of genes with enhanced non-supervised orthologous groups, species and functional annotations. Nucleic Acids Res 2010, 38(Database):D190-195

122. Tatusov RL, Fedorova ND, Jackson JD, Jacobs AR, Kiryutin B, Koonin EV, Krylov DM, Mazumder R, Mekhedov SL, Nikolskaya AN, et al: The COG database: an updated version includes eukaryotes. Bmc Bioinformatics $2003,4$.

doi:10.1186/1752-0509-6-S3-S5

Cite this article as: Cai et al:: Module-based subnetwork alignments reveal novel transcriptional regulators in malaria parasite Plasmodium falciparum. BMC Systems Biology 2012 6(Suppl 3):S5.

\section{Submit your next manuscript to BioMed Central and take full advantage of:}

- Convenient online submission

- Thorough peer review

- No space constraints or color figure charges

- Immediate publication on acceptance

- Inclusion in PubMed, CAS, Scopus and Google Scholar

- Research which is freely available for redistribution 